\title{
Reaproveitamento de medicamentos para a COVID-19: aconselhável ou não?
}

Reuse of drugs for COVID-19: advisable or not?

Reutilización de fármacos para el COVID-19: aconsejable o no?

Alyne Maria da Costa Barbosa ORCID: https://orcid.org/0000-0002-8660-6534

Universidade Federal de Alfenas, Brasil

E-mail: alyne.barbosa@ sou.unifal-mg.edu.br

Amanda Magri Dias

ORCID: https://orcid.org/0000-0001-7801-1090

Universidade Federal de Alfenas, Brasil

E-mail: amanda.magri@ sou.unifal-mg.edu.br

Gabriel Carvalho Lambert

ORCID: https://orcid.org/0000-0001-9276-3010

Universidade Federal de Alfenas, Brasil

E-mail: gabriel.lambert@ sou.unifal-mg.edu.br

Josiane Oliveira Freire

ORCID: https://orcid.org/0000-0002-1345-4736 Universidade Federal de Alfenas, Brasil

E-mail:josiane.freire@sou.unifal-mg.edu.br

Julia Cristina Marques

ORCID: https://orcid.org/0000-0002-9574-2431 Universidade Federal de Alfenas, Brasil

E-mail: julia.marques@sou.unifal-mg.edu.br

Karolline de Oliveira Santana

ORCID: https://orcid.org/0000-0002-1883-4316

Universidade Federal de Alfenas, Brasil

E-mail: karolline.santana@sou.unifal-mg.edu.br

Kerolaine da Silva Silvério

ORCID: https://orcid.org/0000-0002-7449-7430 Universidade Federal de Alfenas, Brasil

E-mail: kerolaine.silverio@sou.unifal-mg.edu.br

Larissa Vitória Marcacini

ORCID: https://orcid.org/0000-0003-2560-5287

Universidade Federal de Alfenas

E-mail: larissa.marcacini@ sou.unifal-mg.edu.br

Maria Eduarda Tavares de Lima

ORCID: https://orcid.org/0000-0001-9646-9206 Universidade Federal de Alfenas, Brasil

E-mail: maria.tavares@sou.unifal-mg.edu.br

Patrick Augusto Quintino Pinto

ORCID: https://orcid.org/0000-0001-5523-6203 Universidade Federal de Alfenas, Brasil

E-mail:patrick.pinto@sou.unifal-mg.edu.br Stefane Neves Lemes da Silva

ORCID: https://orcid.org/0000-0002-8993-4920 Universidade Federal de Alfenas, Brasil

E-mail: stefane.silva@sou.unifal-mg.edu.br

Tainá Stenico da Costa

ORCID: https://orcid.org/0000-0002-9578-421X Universidade Federal de Alfenas, Brasil

E-mail: taina.costa@sou.unifal-mg.edu.br

Uéverton Batista Viotrino

ORCID: https://orcid.org/0000-0001-7770-264X Universidade Federal de Alfenas, Brasil E-mail: ueverton_batista@hotmail.com

Yan Victor Carvalho Cruz

ORCID: https://orcid.org/0000-0002-6151-0026 Universidade Federal de Alfenas, Brasil E-mail: yan.cruz@sou.unifal-mg.edu.br

Fernanda Borges de Araújo Paula ORCID: https://orcid.org/0000-0003-3077-3023 Universidade Federal de Alfenas, Brasil

E-mail: fernanda.paula@unifal-mg.edu.br 


\begin{abstract}
Resumo
Com a pandemia de COVID-19 surgiu a necessidade da busca de medicamentos para o tratamento e prevenção da doença. Consequentemente, houve o reaproveitamento de alguns fármacos. Dessa forma, o presente estudo teve como objetivo realizar uma revisão dos fármacos cloroquina, hidroxicloroquina e ivermectina, ressaltando os mecanismos de ação, os estudos que comprovam- ou não- sua eficácia sob o SARS-CoV-2 e os principais efeitos adversos relacionados ao uso irracional, compreendendo se o uso desses medicamentos deve ser aconselhado ou não. A revisão de literatura foi baseada em artigos científicos indexados nas bases de dados Pubmed e Portal de Periódicos Capes publicados nos últimos 3 anos, usando os descritores "Use of medicines"; "COVID-19"; "Self-medication" e "Rational use of". A partir da análise de 27 artigos, verificou-se que muitos estudos in vitro e clínicos foram realizados, porém, mostram-se controversos. Dessa forma, o uso desses medicamentos de modo irracional, como vem ocorrendo, traz riscos à saúde. Torna-se necessário a existência de estudos clínicos mais complexos e sérios para que um resultado não conflitante seja levado como referência.
\end{abstract}

Palavras-chave: COVID-19; Cloroquina; Hidroxicloroquina; Ivermectina; Uso irracional de medicamentos.

\begin{abstract}
With the COVID-19 pandemic, the need for the search for medicines for the treatment and prevention of the disease arose. Consequently, some drugs were reused. Thus, the present study aimed to conduct a review of the drugs chloroquine, hydroxychloroquine and ivermectin, highlighting the mechanisms of action, studies that prove- or nottheir efficacy goes to SARS-CoV-2 and the main adverse effects related to irrational use, understanding whether the use of these drugs should be advised or not. The literature review was based on scientific articles indexed in the Pubmed databases and Portal of Capes Journals published in the last 3 years, using the descriptors "Use of medicines"; "COVID19"; "Self-medication" and "Rational use of". From the analysis of 27 articles, it was found that many in vitro and clinical studies were conducted, however, they are controversial. Thus, the use of these drugs in an irrational way, as has been occurring, brings health risks. It is necessary to have more complex and serious clinical studies in case of a non-conflicting result being taken as a reference.
\end{abstract}

Keywords: COVID-19; Chloroquine; Hydroxychloroquine; Ivermectin; Irrational use of medicines.

\title{
Resumen
}

Con la pandemia del COVID-19 surgió la necesidad de buscar medicamentos para el tratamiento y la prevención de la enfermedad. En consecuencia, algunos medicamentos fueron reutilizados. Así, el presente estudio tuvo como objetivo realizar una revisión de los fármacos cloroquina, hidroxicloroquina e ivermectina, destacando los mecanismos de acción, los estudios que demuestran -o no- su eficacia va al SARS-CoV-2 y los principales efectos adversos relacionados con el uso irracional, entendiendo si se debe aconsejar o no el uso de estos fármacos. La revisión de la literatura se basó en artículos científicos indexados en las bases de datos Pubmed y Portal of Capes Journals publicados en los últimos 3 años, utilizando los descriptores "Uso de medicamentos"; "COVID-19"; "Automedicación" y "Uso racional de". A partir del análisis de 27 artículos, se encontró que se realizaron muchos estudios in vitro y clínicos, sin embargo, son controvertidos. Así, el uso de estos fármacos de forma irracional, como ha estado ocurriendo, conlleva riesgos para la salud. Es necesario contar con estudios clínicos más complejos y serios en caso de que se tome como referencia un resultado no conflictivo.

Palabras clave: COVID-19; Cloroquina; Hidroxicloroquina; Ivermectina; Uso irracional de medicamentos.

\section{Introdução}

Descoberto no final de dezembro de 2019, após um surto de pneumonia em Wuhan, província de Hubei, na China, o novo Coronavírus se espalhou rapidamente pelo mundo, sendo declarada uma pandemia em 11 de Março de 2020 , pela Organização Mundial da Saúde. Decorrente da sua semelhança genética à variantes já descobertas, o patógeno recebeu inicialmente a nomenclatura oficial de SARS-CoV-2, por ser pertencente à mesma família dos Coronavírus responsáveis pela Síndrome Respiratória Aguda Grave (SARS-CoV) e Síndrome Respiratória do Mediterrâneo (MERS-CoV), também causadores de surtos em 2002 e 2012, respectivamente (Singh \& Gupta, 2021). O grupo dos coronavírus é diverso, englobando vários tipos de vírus envelopados de senso-positivo e de RNA de fita simples, causadores de doenças de trato respiratório, entérico, hepático e neurológico em humanos e animais (He et al., 2020).

A COVID-19 (Nomenclatura dada à doença causada pelo SARS-CoV-2) pode se apresentar de forma sintomática ou não, tendo como principais sintomas febre, fadiga, tosse seca e dores musculares. Além disso, o quadro clínico dos pacientes pode ser classificado de acordo com a severidade dos sintomas apresentados, variando entre a forma mais leve, quando não 
apresentam quadro de pneumonia ou apresentam-na de forma branda, podendo haver progressão para quadro severo afetando sistema respiratório e podendo culminar na forma crítica da doença, quando há falha respiratória, choque séptico e falha/disfunção de múltiplos órgãos, levando a óbito (He et al., 2020).

O crescente número de casos ao redor do mundo e o aumento do número de óbitos decorrentes do colapso dos sistemas de saúde mundiais resultaram numa intensa busca por medicamentos para o tratamento da doença. Nesse cenário de urgência, medicamentos utilizados para outras enfermidades foram alvo de estudos em tentativa de encontrar terapias efetivas para o problema, como os utilizados para Influenza, HIV e outros vírus, antibióticos, como a azitromicina, anti-helmínticos, tendo destaque a ivermectina, e anti-maláricos, como a cloroquina (CQ) e hidroxicloroquina (HCQ) (Paumgartten \& Oliveira, 2020). Porém, a ausência de resultados expressivos no tratamento ou profilaxia, bem como a falta de robustez de muitos ensaios clínicos publicados fizeram com que órgãos governamentais e profissionais de saúde recorressem à práticas clínicas não sustentadas nas melhores evidências científicas, prescrevendo e utilizando medicamentos sem demonstração real de eficácia contra a COVID19, não compatível com as diretrizes de uso racional de medicamentos (URM) da Organização Mundial da Saúde (Paumgartten \& Oliveira, 2020).

Tendo em vista o aumento drástico da automedicação e do uso indiscriminado de muitos medicamentos, a presente revisão tem como objetivo discutir sobre o uso dos principais fármacos utilizados no tratamento do SARS-CoV-2, esclarecendo seus mecanismos de ação e apresentando estudos que comprovam ou não sua eficácia, bem como os efeitos adversos decorrentes de seu uso.

\section{Metodologia}

O presente estudo trata-se de uma revisão narrativa, que teve como objetivos fornecer um panorama sobre os principais medicamentos utilizados empiricamente no tratamento da Covid-19, CQ, HCQ e ivermectina, com ênfase nos seus efeitos adversos decorrentes do uso irracional.

A seleção dos artigos foi baseada na metodologia adotada por Froes et al. (2020) com algumas modificações e está representada na Figura 1. Para tanto, foram avaliados artigos das plataformas Pubmed e Portal de Periódicos Capes publicados nos últimos 3 anos, de 2019 a 2021 por meio da busca dos termos: "Use of medicines"; "Covid-19”; "Self-medication"; "Rational use of'. Os critérios utilizados para a inclusão foram o artigo se tratar de estudos experimentais ou artigos de revisão envolvendo os malefícios do uso irracional algum dos três medicamentos citados anteriormente ou a sua ação sobre o vírus SARS-CoV-2, publicados em inglês, português e espanhol. Foram excluídos, os artigos que não abordaram a temática em estudo, artigos de opinião e estudos não publicados no formato de artigo completo.

Inicialmente, foi obtida com a busca um total de 720 artigos, dos quais 56 artigos foram selecionados para leitura do título e resumo. Em seguida, foi realizada uma análise do desenho experimental, dos métodos adotados e dos resultados das pesquisas a fim de determinar a relevância destes estudos e 47 artigos foram selecionados para leitura na íntegra. Entre estes, 27 artigos foram selecionados para compor esta revisão. As evidências científicas foram extraídas destes artigos, resumidas e organizadas de modo a oferecer ao leitor, um panorama sobre as principais condutas e teorias baseadas em informações científicas acerca da temática em questão. 
Figura 1. Fluxograma da pesquisa e seleção dos artigos.
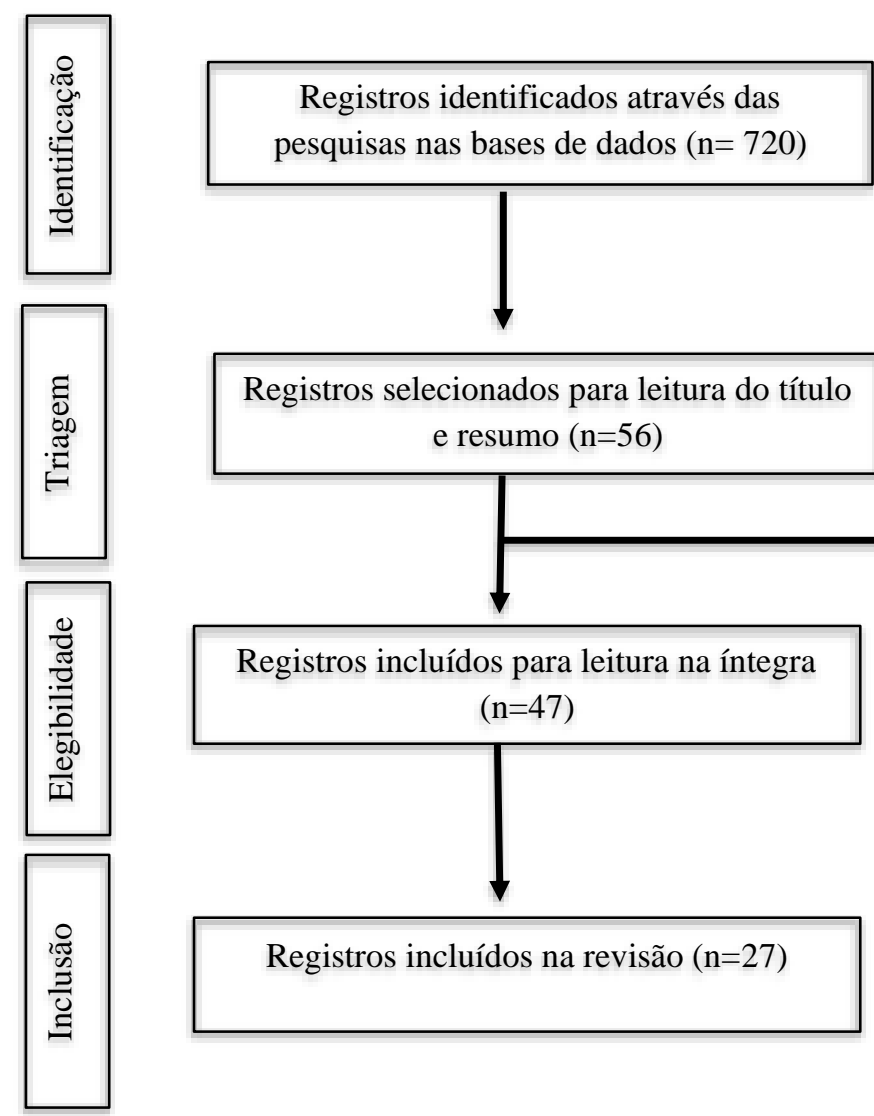
resumo $(n=9)$

Fonte: Autores (2021);

\section{Resultados e Discussão}

\subsection{Cloroquina}

Considerado como um fármaco pertencente ao grupo de derivados de 4-aminoquinolina (Zou et al., 2020), a Cloroquina, um medicamento sintético, foi descoberta pela primeira vez em 1934 e o seu valor terapêutico foi comprovado somente dez anos após as primeiras investigações. Em 1947, a CQ foi aprovada para a profilaxia da malária, e posteriormente adicionada à lista de medicamentos essenciais da Organização Mundial da Saúde (OMS). Dentre de seus alvos clínicos, destaca-se a malária não complicada, tratamento da amebíase extra-intestinal, além de apresentar em estudos clínicos, efeitos anti-inflamatórios e imunomoduladores. Ademais, é uma droga utilizada como tratamento potencial para um amplo espectro de doenças, incluindo doenças infecciosas e não infecciosas, uma ampla gama de cânceres, lúpus eritematoso sistêmico, esclerose múltipla progressiva primária, esclerose sistêmica e artrite reumatoide (Mallhi et al., 2020).

A CQ é essencialmente desenvolvida a partir da casca de uma planta pertencente ao gênero Cinchona, e a família Rubiaceae. É uma base fraca, solúvel em água, sendo rapidamente absorvida e direcionada ao alvo terapêutico. Apresenta uma meia vida longa de duração no plasma sanguíneo, estimando 900 a 1300 horas, logo é excretada lentamente no organismo humano, necessitando de um monitoramento contínuo mesmo após a parada da medicação (Pereira, 2020).

Estudos recentes apontam que medicamentos antimaláricos possuem atividades antivirais in vitro e clínicas contra o SARS-CoV-1 e o SARS-CoV-2. A CQ foi um dos medicamentos em destaque entre os pesquisadores e com potencial esperança de tratamento para a COVID-19 no início da pandemia (Hussain et al., 2021).

A dose de CQ deve ser idealmente baseada na altura e peso corporal. Portanto, a sexta edição do Novo Plano de Diagnóstico e Tratamento de Pneumonia por Coronavírus da China, publicado pela Comissão Nacional de Saúde da China, 
dialoga sobre as possíveis doses de CQ frente ao tratamento COVID-19. Em suma, salienta-se que quando o peso corporal do paciente é maior que $50 \mathrm{~kg}$, uma dose oral de 500mg de fosfato de CQ é recomendada duas vezes ao dia. Todavia, pacientes com peso corporal menor que $50 \mathrm{~kg}$, a dose de recomendação é $500 \mathrm{mg}$, duas vezes ao dia durante os primeiros dois dias de tratamento, e nos próximos cinco dias, a frequência da medicação deve ser ajustada a somente uma vez ao dia, visando diminuição de possíveis efeitos colaterais (Zou et al., 2020).

Houve uma busca desenfreada ao medicamento, principalmente no Brasil, visto a quantidade de informações vinculadas à mídia e por autoridades representativas de que essa seria uma alternativa promissora ao tratamento da COVID-19, permeando a uma ameaça à disponibilidade da CQ no mercado. Ressalta-se neste sentido o perigo da automedicação, essencialmente pelo potencial de causar efeitos adversos substanciais, pouco elucidados frente aos estudos clínicos realizados em um centro com relação ao tratamento do vírus SARS-CoV-2 (Mallhi et al., 2020). Salientando então, a falta de evidências clínicas em ensaios multicêntricos, e com acompanhamentos aos pacientes à longo prazo, de modo a destacar a incidência de efeitos colaterais $\mathrm{e}$ toxicidade (Zou et al., 2020). Os principais desafios aqui postos são considerar o máximo possível de aspectos epidemiológicos e clínicos antes de iniciar o tratamento, e disseminar a maior quantidade de informações médicas baseadas em evidências científicas (Mallhi et al., 2021).

\subsubsection{Mecanismo de ação da cloroquina}

A CQ, após entrar em contato com as células, induz no organismo um aumento do $\mathrm{pH}$ em organelas ácidas, incluindo os endossomos, lisossomas e vesículas de Golgi, de modo a destruí-las. Destacando que o ambiente alcalino criado não é um lugar propício para a multiplicação viral, diferentemente do que ocorre com pH baixo (Zou et al., 2020).

$\mathrm{O}$ aumento do $\mathrm{pH}$ intracelular induzido pela administração da CQ atua sequestrando os prótons em lisossomas, culminando em afetar a fusão, o desencapsulamento e a replicação viral (Nina \& Dash, 2020). Em específico, o processo de desencapsulamento viral é prejudicado quando o pH lisossomal é superior ao valor crítico necessário para induzir a fusão entre o envelope viral e a membrana lisossomal (Zou et al., 2020).

Além dos efeitos destacáveis acerca do $\mathrm{pH}$ da célula, a CQ pode afetar a replicação viral ao inibir a expressão do gene viral. Experimentos in vitro e in vivo apontam que pode ocorrer uma alteração no padrão de glicosilação de glicoproteínas, impedindo a replicação viral (Zou et al., 2020).

Nesse sentido, é de suma importância contextualizar quanto ao mecanismo de ação perante aos efeitos imunomoduladores e inflamatórios da droga. Ao induzir o aumento do $\mathrm{pH}$ dentro dos vacúolos intracelulares, ocorre a alteração das hidrólises ácidas e por conseguinte, interferência na montagem molecular necessária ao processamento do antígeno peptídico. Dessa maneira, ocorre uma diminuição no estímulo da resposta com relação às células TCD4, permeando ainda, na diminuição na secreção de citocinas essenciais ao desenvolvimento da reação anti-inflamatória, como o Interferon Gama (TNF $\alpha$ ), IL-1, IL2 e IL-6, essencialmente em células mononucleares do sangue periférico humano (Dragojevic Simic et al., 2020).

A CQ sendo um medicamento com baixo custo e relativamente seguro, é amplamente utilizado para a inibição da replicação viral. Desse modo, alguns pesquisadores sugeriram que poderia ser um inibidor eficaz perante a replicação do SARSCoV-2. Os resultados in vitro salientam que a CQ é capaz de ocasionar um comprometimento na fusão do vírus na célula devido ao pH endossômico aumentando, e também ocasionar uma interferência na glicosilação terminal dos receptores ACE-2 celulares, imprescindíveis para a entrada do vírus SARS-CoV na célula. Tais alterações resultam na diminuição da afinidade dos receptores ACE-2 com as proteínas spike do SARS-CoV, potencialmente prevenindo a infecção (Dragojevic Simic, 2020).

Em níveis elevados de pH lisossomal a CQ reduz os níveis de catepsina, uma família de proteases da cisteína, resultando na formação de autofagossomo, sendo este responsável pela clivagem da proteína spike SARS-CoV-2 (Hussain et al., 2021). 
Além disso, o controle dos processos inflamatórios desencadeados pela infecção do Novo Coronavírus se mostra fundamental, nesse sentido, a CQ é responsável pela redução na produção de citocinas pró-inflamatórias e outros mediadores (Pereira, 2020).

\subsubsection{Estudos da atividade do fármaco contra o SARS-CoV-2}

Atualmente é debatido com grande recorrência o uso da CQ para pacientes com COVID-19, uma vez que é sugerido que este fármaco possui potencial eficácia frente ao SARS-CoV-2, responsável pela doença citada anteriormente (Hussain et al., 2021). In vitro, o medicamento possui atividade substancial contra o vírus (Willis et al., 2020), e apresentou capacidade para inibir a infecção viral, assim, sugerindo que há efeito profilático em seu uso, além de evitar que haja propagação do vírus após 5h da infecção (Klimke et al., 2020).

O primeiro estudo clínico com uma amostra superior a 100 pacientes, realizado com CQ foi capaz de demonstrar que o medicamento inibiu a exacerbação da pneumonia (Klimke et al., 2020), fazendo com que houvesse melhoria nos achados de imagem pulmonar e, também promoveu a conversão viral negativa e reduziu a doença sem apresentar reações adversas (Klimke et al., 2020; Nina \& Dash, 2020).

Neste viés, a CQ possui efeitos anti SARS-CoV-2, tanto in vitro como in vivo, se tornando um grande potencial para tratamento da COVID-19. Entretanto, ainda se espera novas pesquisas clínicas multicêntricas, tendo em vista que os ensaios clínicos realizados até o momento são provenientes de um mesmo centro (Zou et al., 2020).

Em suma, os resultados clínicos obtidos são conflitantes, pois em alguns casos são feitas administrações concomitantes a outros medicamentos. Ademais, quanto aos estudos farmacocinéticos, é ressaltada uma preocupação em relação à segurança das dosagens utilizadas na atualidade, uma vez que é questionada a real capacidade do fármaco para atingir as concentrações mínimas para exercer sua atividade antiviral (Willis et al., 2020).

Por fim, se faz necessário novos estudos em centros distintos, como supracitado, de modo a contemplar uma maior gama de informações referente a $\mathrm{CQ}$, com desenhos clínicos adequados, utilizando amostras maiores, bem como manter um grupo controle com a utilização de placebo e estabelecimento de critérios para exclusão (Dragojevic Simic et al., 2021).

\subsubsection{Principais efeitos adversos do uso da cloroquina}

Se usado em concordância com a prescrição, a CQ possui um padrão de segurança adequado, sendo segura também para crianças e gestantes. Entretanto, vale salientar que existem algumas contraindicações - demasiadamente fatais, à sua utilização na terapêutica (Mallhi et al., 2020).

Quando administrada por longos períodos, a CQ apresenta efeitos adversos graves (Zou et al., 2020). Nesta mesma vertente, é observado que quando há emprego de altas doses de CQ, os efeitos preocupantes tornam-se mais evidentes (Mallhi et al., 2020; Belayneh, 2020), assim, dosagens elevadas exaltam riscos potenciais, não sendo sugeridas para pacientes que se encontram com quadros críticos causados pela COVID-19 (Belayneh, 2020).

Num contexto geral, náuseas, vômitos e diarreia são alguns dos efeitos colaterais leves mais prevalentes durante o uso da CQ (Dragojevic Simic et al., 2021). Além disso, também são incluídos efeitos como tontura, alterações do paladar, irritabilidade e dor de cabeça, por exemplo (Zou et al., 2020).

Quanto aos efeitos graves, alguns dos descritos são: retinopatia e cardiomiopatia (Belayneh, 2020; Paumgartten \& Oliveira, 2020). É interessante citar que a retinopatia pode ocasionar problemas oftalmológicos irreversíveis, como a perda de visão (Zou et al., 2020).

Se pautando em pacientes com COVID-19 que possuem transtornos pré-existentes no coração, a suscetibilidade aos problemas de ritmo cardíaco é aumentada com utilização da CQ (Belayneh, 2020). O uso do medicamento também possibilita a 
visualização de efeitos dermatológicos, como fotossensibilidade e prurido; quando administrada por via intramuscular, a CQ se correlaciona a hipotensão, além do fármaco em questão induzir hemólise (Mallhi et al., 2020).

Ademais, quando ocorre uso indiscriminado da $\mathrm{CQ}$, seja por períodos prolongados ou por doses excessivas, podem ser desencadeadas neuropatias nos pacientes (Hussain et al., 2021; Pereira, 2020), além de problemas neurológicos específicos como convulsões, alucinações e paranoias (Mallhi et al., 2020).

Por fim, a utilização da CQ na terapêutica torna possível o aparecimento de efeitos indesejados aos níveis: hepático e renal, bem como a overdose desta droga pode acarretar, devido sua alta toxicidade, problemas maiores como parada cardíaca e coma (Belayneh, 2020).

\subsection{Hidroxicloroquina}

A HCQ é um antimalárico que teve aprovação efetivada pelo FDA nos anos de 1955, trata-se de um medicamento derivado da CQ que apresenta menor toxicidade em relação a mesma. Além de ser prescrito para tratamento de pacientes com malária, também é comumente observado nas prescrições em casos de artrite reumatoide (AR) e lúpus eritematoso sistêmico (Singh \& Gupta, 2021). Esse medicamento foi desenvolvido a partir da casca de cinchona (Rubiaceae), possui uma absorção rápida e meia vida longa, de aproximadamente 1300 horas e é metabolizado pelo complexo citocromo P450 no fígado, sendo que 50\% dos metabólitos são excretados sem modificação pelos rins (Pereira, 2020).

Assim como a CQ, a HQC pertence ao grupo de derivados de 4-aminoquinolina e por esse motivo compartilham de propriedades farmacológicas semelhantes. Nesse sentido, sabe-se que a concentração sanguínea do fármaco mais elevada é atingida de 1 a 2 horas após sua ingestão. A concentração da HCQ no pulmão, rim, fígado e baço é de 200 a 700 vezes maior que a concentração no sangue, enquanto que no cérebro e nos tecidos da medula espinhal essa concentração é de 10 a 30 vezes maior (Zou et al., 2020).

Ademais, a HQC possui um substituinte $\mathrm{N}$-etil hidroxilado de $\mathrm{CQ}$, tem alto volume de distribuição aparente (525 \pm 158 $\mathrm{L} / \mathrm{kg}$ ), sendo lentamente liberado nos tecidos e possui uma biodisponibilidade oral de $79 \pm 12 \%$ e é $45 \pm 3 \%$ ligado ao plasma (Kaur et al., 2020). Por fim, o principal metabólito da HCQ é a desetilcloroquina e a taxa de depuração desse fármaco é baixa (Zou et al., 2020).

Como relatado anteriormente, a HCQ foi usada inicialmente para fins de tratamento de pacientes com malária. No entanto, alguns efeitos anti-inflamatórios, imunomoduladores, anti infecciosos, anti trombóticos e metabólicos foram observados e por esse motivo até o presente momento, esse medicamento foi tido como terapia de uma variedade de doenças infecciosas, reumatóides e outras doenças imunológicas. Além desses fatores, efeitos antivirais foram identificados na ação da HCQ (Zou et al., 2020).

\subsubsection{Mecanismo de ação da hidroxicloroquina}

A CQ e a hidroxicloroquina compartilham a estrutura química e possuem mecanismo de ação semelhante, mas a hidroxicloroquina é menos tóxica devido a um grupo extra de hidroxila presente que mostra baixa permeabilidade à barreira hemato-ocular e permite rápida eliminação das células pigmentares da retina. Os testes realizados in vitro, demonstraram que o sulfato de hidroxicloroquina é potencialmente mais rápido na inibição de SARS-CoV-2 quando comparado a cloroquina (Hussain et al., 2021).

De acordo com Nina e Dash (2021), estudos demonstram que a HCQ apresenta efetividade contra a hepatite C por aumentar a resposta virológica precoce contra essa doença, além de reduzir a carga de HIV-1 e ter propriedades imunossupressoras que podem auxiliar na redução de citocinas em COVID - 19 grave. 


\subsubsection{Estudos da atividade do fármaco contra o SARS-CoV-2}

No atual cenário pandêmico vivenciado mundialmente, diversos estudos foram desenvolvidos com o objetivo de verificar possíveis medicamentos eficazes no tratamento da COVID-19, como a HCQ. Enquanto uma variedade de estudos relatou eficácia deste medicamento, outros o consideram ineficaz e alguns ainda relataram diversos efeitos adversos do uso de HCQ em indivíduos afetados pela COVID-19 (Singh \& Gupta, 2021).

Devido aos efeitos anti-inflamatórios e imunomoduladores e aumento do $\mathrm{pH}$ endossômico, estudos demonstraram que a HCQ apresentou atividade in vitro contra o vírus SARS-CoV-2. Dessa maneira, no dia 28 de março de 2020, foi aprovado pelo FDA o uso emergencial da HCQ para pacientes adultos com COVID-19. No entanto, no dia 15 de junho de 2020, essa aprovação foi revogada levando em consideração o risco potencial associado ao uso deste medicamento (Singh \& Gupta, 2021).

Além dos resultados in vitro, foram observados efeitos in vivo no uso clínico da HCQ, mas apesar disso, os efeitos desse medicamento no tratamento da COVID-19 são ainda muito controversos. Nesse sentido, a Agência Europeia de Medicamentos (EMA) permitiu o uso desse medicamento seja apenas para fins de ensaios clínicos e recomendou que seu uso emergencial esteja de acordo com as políticas de cada país (Zou et al., 2020).

Dentre os diversos estudos realizados a fim de verificar a eficácia da HCQ contra o SARS-CoV-2, pode-se citar como exemplo, um ensaio aberto, não randomizado feito por Gautret e colaboradores (2020), em que do total de 36 pacientes com COVID-19, 26 receberam a HCQ e 6 desses também receberam azitromicina. Os autores observaram que 100\% dos pacientes que receberam azitromicina e hidroxicloroquina foram testados negativamente com COVID-19 após 6 dias de tratamento. Em relação aos pacientes que receberam apenas a $\mathrm{HCQ}, 57,1 \%$ apresentaram resultados negativos e 12,5\% no grupo controle. Dessa maneira, os autores concluíram nesse estudo que a HCQ é uma droga potente para eliminar o vírus SARS-CoV-2, principalmente quando associada a azitromicina, apesar das limitações metodológicas encontradas, como o número pequeno de amostras utilizadas e a falta de randomização (Singh \& Gupta, 2021; Lucchetta \& Mastroianni, 2019).

Ao contrário dos resultados relatados por Singh \& Gupta (2021), estudos demonstrando resultados desfavoráveis ao uso da HCQ no tratamento da COVID 19 também foram encontrados na literatura. Tem-se como exemplo o fato de que Molina e colaboradores (2020) não encontraram evidências clínicas ao utilizar HCQ e azitromicina nas mesmas dosagens descritas no estudo de Gautret e colaboradores em 11 pacientes com COVID-19 graves e com comorbidades significativas. Tang e colaboradores (2020) não encontraram nenhum benefício significativo em um estudo clínico aberto, randomizado e controlado com a presença de 75 pacientes (Singh \& Gupta, 2021). Reforça-se ainda, com o estudo de Maisonnasse e colaboradores (2020) onde o teste de HCQ em primatas não humanos não demonstrou eficácia antiviral independentemente do momento do início do tratamento (Maisonnasse et al., 2020)

Dessa forma, tendo em vista diversas mudanças rápidas nas diretrizes de saúde bem como a existência de novas evidências, não se tem total clareza em relação ao tratamento e profilaxia da COVID-19 utilizando HCQ (Kaur et al., 2020).

\subsubsection{Principais efeitos adversos do uso da hidroxicloroquina}

Sabe-se que grande parte dos medicamentos estudados no combate à SARS-CoV-2 apresentam toxicidades ao organismo humano, apresentando efeitos adversos como cardiotoxicidade, nefrotoxicidade, hepatotoxicidade e toxicidade hematológica. Em relação aos efeitos adversos ocasionados pela hidroxicloroquina, destacam-se os distúrbios cardíacos, como o prolongamento do segmento QT, que pode levar à arritmia e parada do miocárdio sendo capaz de desencadear problemas como retinopatia, neuromiopatia e cardiomiopatia (Nina \& Dash, 2020).

Nesse sentido, evidencia-se que a retinopatia desencadeada pelo medicamento em questão é devido ao mesmo ter a capacidade de causar alterações não reversíveis nos fotorreceptores. Isso porque, a hidroxicloroquina apresenta certa afinidade 
pelas moléculas da melanina podendo reagir com os segmentos externos dos fotorreceptores que são desencadeados pela ação desse medicamento, resultando na redução da atividade fagocítica dos lisossomas nos segmentos externos do fotorreceptor, induzindo a atrofia epitelial. Além disso, os efeitos tóxicos do medicamento que favorecem o desencadeamento da neuromiopatia e cardiomiopatia são baseados no seu acúmulo dentro dos lisossomas que inibem as fosfolipases lisossomais ocasionando a vacuolização das células musculares cardíacas e esqueléticas (Pereira, 2020).

Do mesmo modo, estudos denotam que este medicamento administrado por via oral, pode causar efeitos colaterais graves, variando de sintomas psiquiátricos à toxicidade ocular e à disfunção miocárdica, principalmente quando ocorre superdosagem. Assim, devido a possibilidade desses efeitos colaterais serem graves, a aplicação generalizada in vivo é limitada. Pela perspectiva farmacológica, isso ocorre pelo fato do medicamento muitas vezes não atingir diretamente a superfície dos pulmões que seria o alvo e ser metabolizado internamente, o que exige que essa droga seja administrada em dosagens orais relativamente altas para inibir a glicosilação do receptor ACE2 solúvel na superfície alveolar do pulmão. Isso porque, nas regiões pulmonares, a biodisponibilidade da hidroxicloroquina é dependente da reabsorção intestinal, do metabolismo hepático de primeira passagem e da difusão do sangue para as células alveolares, que seria compensada se o medicamento fosse administrado em altas concentrações. Contudo, as dosagens altas são limitadas devido aos efeitos adversos que são potencialmente tóxicos ao organismo (Klimke et al., 2020).

\subsection{Ivermectina}

A ivermectina foi descoberta em 1967, no Instituto Kitasato, no Japão, e seu primeiro uso se deu no tratamento da oncocercose, causada por Onchocerca volvulus e transmitida pela mosca negra em humanos (Kaur et al., 2021). É um medicamento semi-sintético, análogo do produto natural avermectina B1a, isolado da Streptomyces avermitilis (Momekov \& Momekova, 2020).

Atua como anti-helmíntico, seguro e eficaz contra vários ectoparasitas e endoparasitas, além de apresentar propriedades antibacterianas, anticâncer, antiviral, antimitóticas e antialérgicas (Mohan et al., 2020; Momekov \& Momekova, 2020). Além disso, também apresenta importante atividade no tratamento da malária, da tripanossomíase, leishmaniose, piolhos, e é eficaz no tratamento de infecções filariais e erradicação de parasitas no trato gastrointestinal (Kaur et al., 2021).

Devido a esta propriedade antiviral, e atividade contra os vírus HIV-1 e dengue, entre outros em estudos in vitro, a utilização da ivermectina contra o SARS-COV-2 tornou-se uma esperança e uma possível alternativa de tratamento (Mohan et al., 2020; Singh \& Gupta, 2021; Kern et al., 2021).

Além disso, a ivermectina apresenta amplo espectro contra vários parasitas de humanos, animais domésticos e animais de estimação. No caso de humanos, este medicamento atua na oncocercose e estrongiloidíase, e em animais, é ativo contra carrapato do gado, Rhipicephalus microplus, a lagarta do barbeiro, Haemonchus contortus, e a sarna, Sarcoptes scabiei (Mohan et al., 2020). No Quadro 1, estão representadas as espécies com evidência de inibição pela ivermectina, que apesar de apresentarem resultados significativos in vitro, ainda apresentam resultados contraditórios e limitados em estudos in vivo (Mohan et al., 2020). 
Quadro 1. Ação da ivermectina contra espécies virais.

\begin{tabular}{|c|c|}
\hline \multicolumn{2}{|c|}{ Vírus de DNA } \\
\hline Ação in vivo & Ação in vitro \\
\hline Parvovírus & Herpesvírus equino tipo 1 \\
\hline Circovírus suíno 2 & Vírus da pseudo-raiva \\
\hline Vírus da pseudo-raiva & BK poliomavírus \\
\hline & Circovírus suíno 2 \\
\hline \multicolumn{2}{|c|}{ Vírus de RNA } \\
\hline Ação in vivo & Ação in vitro \\
\hline Zika vírus & SARS-CoV-2 \\
\hline Dengue vírus & Zika vírus \\
\hline \multirow[t]{9}{*}{ Vírus newcastle } & Dengue vírus \\
\hline & Febre amarela \\
\hline & Vírus do Nilo Ocidental \\
\hline & Hendra vírus \\
\hline & Vírus Newcastle \\
\hline & Vírus Chikungunya \\
\hline & Vírus da gripe aviária \\
\hline & Vírus da síndrome reprodutiva e respiratória suína \\
\hline & Vírus da imunodeficiência humana \\
\hline
\end{tabular}

Fonte: Adaptado de Mohan et al. (2020).

O regime terapêutico da ivermectina é variável de acordo com a doença tratada, nos casos de tratamento da oncocercose, deve utilizar $150 \mu \mathrm{g} / \mathrm{kg}$ uma vez por ano, para estrongiloidíase, 150 a $200 \mu \mathrm{g} / \mathrm{kg}$ duas vezes ao ano ou, alternativamente, para áreas endêmicas para filariose, recomenda-se a utilização de 300 a $400 \mu \mathrm{g} / \mathrm{kg}$ uma vez por ano, e em casos de sarna hiperceratótica, também chamada de escabiose em crosta, recomenda-se $200 \mu \mathrm{g} / \mathrm{kg}$ em conjunto com medicamentos tópicos (Momekov \& Momekova, 2020).

A ivermectina é utilizada por via oral e é absorvida no trato gastrointestinal, atingindo um pico de concentração plasmática de 20-50 ng / dl após as doses de 6 e 12 mg e leva cerca de quatro horas para atingir sua concentração plasmática máxima. Sua metabolização ocorre, em maior parte, no fígado pelo sistema enzimático microssomal hepático CYP3A4, formando vários metabólitos, agindo como um substrato para a glicoproteína P (Mohan et al., 2020).

Além disso, a ivermectina não atravessa a barreira hematoencefálica, já que $93 \%$ deste fármaco se encontra ligado às proteínas plasmáticas e tem tempo de meia vida aproximado de 12 a 24 horas. Sua excreção ocorre principalmente pelas fezes por um período de 12 dias e mínima excreção pela urina (Mohan et al., 2020). 


\subsubsection{Mecanismo de ação da ivermectina}

O mecanismo de ação da ivermectina se baseia na sua ação nos canais de cloreto dependentes do ácido gamaaminobutírico que provocam um aumento na condutância do eletrólito, causando uma hiperpolarização da membrana celular, bloqueando a neurotransmissão inibitória em neurônios e miócitos. Dessa forma, esta ação resulta em paralisia e consequente morte do microrganismo invasor (Mohan et al., 2020).

Além disso, a ivermectina também atua contra várias espécies virais. O efeito antiviral se baseia na inibição do transporte nuclear mediado pelo heterodímero importina $\alpha / \beta 1$, responsável por incorporar a proteína viral nas células hospedeiras.

\subsubsection{Estudos da atividade do fármaco contra o SARS-CoV-2}

$\mathrm{Na}$ busca por uma alternativa rápida de tratamento para a COVID-19, a ivermectina foi um dos fármacos testados contra o vírus SARS-CoV-2, principalmente por ter amplo espectro antiviral.

Entre os diversos estudos realizados para mostrar a eficácia da ivermectina frente ao SARS-CoV-2, um dos principais foi o de Caly e colaboradores (2020), um ensaio in vitro que resultou na redução de aproximadamente 5000 vezes na carga de RNA viral em $48 \mathrm{~h}$.

Por meio de estudos de bioinformática, foi sugerido por Gonzáles-Paz e colaboradores (2021) uma possível ação da ivermectina contra a protease semelhante à quimiotripsina viral 3 (3CLpro), domínio HR2 (proteína de pico), que desempenha todas as funções vitais na replicação viral e na infecção. Segundo os autores, o fármaco pode se ligar sinergicamente à prote ase 3CL e ao domínio HR2, impedindo a replicação do SARS-CoV-2. Além disso, outros estudos sugeriram diferentes mecanismos de ação para a ivermectina na ação contra o SARS-CoV-2, a partir da ligação a ACE2, bem como à proteína S. Notou-se que a especificidade molecular da ivermectina é variada, visto que pode apresentar ligação com os domínios de pico S1 e S2, além do local de inibição da protease CL. Outra possibilidade, refere-se ao fato da ivermectina estar envolvida na inibição da proteína N, que atua na importação celular (Kaur et al., 2021).

Com base na descoberta de Caly e colaboradores (2020), foi estimado que o IC $_{50}$ da ivermectina contra o SARS-CoV2 seria de $2 \mu \mathrm{M}$, o que corresponde a uma concentração plasmática eficaz de $1750 \mathrm{ng} / \mathrm{ml}$ (Mohan et al., 2020).

De acordo com Schmith e colaboradores (2020), a concentração plasmática eficaz é cerca de 25 vezes maior que a concentração plasmática de 46,6 ng / ml, alcançada quando a dose máxima aprovada atualmente, $200 \mu \mathrm{g} / \mathrm{kg}$ é administrada em humanos (Mohan et al., 2020). Portanto, o estudo de Caly et al. (2020) utilizou um delineamento experimental baseado em concentrações inibitórias inatingíveis, mesmo com dosagem excessiva de ivermectina (Momekov \& Momekova, 2020).

Apesar disso, este teste in vitro motivou diversos ensaios clínicos. Poucos deles analisaram o uso de ivermectina como monoterapia, principalmente pela necessidade de doses elevadas. Analisando o uso de ivermectina na dose de $600 \mu \mathrm{g} / \mathrm{kg}$ diariamente, por 3 dias, houve impacto positivo no tratamento em comparação ao uso de hidroxicloroquina. Porém, essa dose, embora possa parecer segura, é muito maior do que aquelas aprovadas para outras indicações (Kern et al., 2021).

Outros pesquisadores demonstraram o impacto positivo da ivermectina para o tratamento da COVID-19, como Rajter e colaboradores (2020), onde realizaram um estudo de coorte retrospectivo $(n=280)$ de pacientes confirmados com infecção por SARS-CoV-2 hospitalizados em um hospital no sul da Flórida, resultando em menores taxas de mortalidade, apesar de não haver diferença na duração da internação hospitalar ou na taxa de intubação entre o grupo controle e o grupo que utilizou ivermectina.

$\mathrm{Na}$ grande maioria dos ensaios clínicos, porém, a ivermectina vem sendo usada em combinação com outros medicamentos contra COVID-19 também em investigação, como a doxiciclina, azitromicina e hidroxicloroquina. Não há justificativas claras para tais combinações, exceto no caso da hidroxicloroquina, onde pode haver um efeito sinérgico, pois ela inibe o SARS-CoV-2 nas células hospedeiras, enquanto a ivermectina aumentaria ainda mais a atividade antiviral ao inibir a 
replicação viral (Mohan et al., 2020). Também são citadas combinações com antivirais como como lopinavir / ritonavir e darunavir / cobicistate, pois eles podem aumentar a concentração sistêmica de ivermectina, por serem inibidores do seu metabolismo ou eliminação (como inibidores da CYP3A4 e o inibidor da glicoproteína P (P-gp)). Entretanto, há preocupações já que a inibição da P-gp pode fazer com que a ivermectina seja distribuída para o sistema nervoso central. A glicoproteína é parte integrante da barreira hematoencefálica, o que levaria a neurotoxicidade (Singh \& Gupta, 2021; Kern et al., 2021).

Em um estudo observacional utilizando a combinação de ivermectina e doxiciclina, Alam et. al (2020) incluíram 100 pacientes com COVID-19 em casos leves ou moderados, tratados com ivermectina (dose única de 0,2 mg / kg) e doxiciclina (100 mg por dia por 10 dias), além de tratamento de suporte. Nenhum efeito colateral foi registrado, os sintomas de todos os pacientes melhoraram em $72 \mathrm{~h}$, a internação em terapia intensiva não foi necessária, nenhuma morte foi relatada e todos os testes foram negativos.

Portanto, apesar de diversos ensaios e estudos estarem disponíveis, os resultados mostram-se em discordância. Os resultados observados, por vezes, são frutos de doses extremamente elevadas ou de combinações que podem trazer riscos à saúde humana.

\subsubsection{Principais efeitos adversos do uso do fármaco}

Quando aplicada nas condições terapêuticas, a ivermectina não está associada a toxicidade significativa, causando efeitos colaterais menores como náuseas, tontura, erupções cutâneas e letargia (Mohan et al., 2020).

Entretanto, apesar da segurança em doses terapêuticas, em grandes doses a droga tem a capacidade de penetrar a barreira hematoencefálica, afetando a transmissão GABAérgica, causando depressão do sistema nervoso central e neurotoxicidade (Momekov \& Momekova, 2020), além de preocupações com efeitos adversos cutâneos e oculares (Mohan et al., 2020).

Com o uso irracional da droga visando o tratamento da COVID-19, overdoses podem se mostrar comuns. Segundo Momekov \& Momekova (2020) quando expostos a overdoses, humanos sofreram vômitos, taquicardias, anormalidades no eletrocardiograma e efeitos no sistema nervoso central, como sonolência e midríase. Além disso, o uso indiscriminado da ivermectina pode gerar consequências como o desenvolvimento de resistência ao anti-helmíntico, tradicionalmente utilizado para este fim (Mohan et al., 2020).

\section{Considerações Finais}

Com base nos dados da presente revisão de literatura, pode-se notar que ainda é muito controversa a indicação de CQ, HCQ e ivermectina para o tratamento ou profilaxia de COVID-19, visto que muitos resultados de estudos já existentes são conflitantes. Neste artigo, foi possível reunir evidências dos três fármacos mais utilizados para essa condição, como o mecanismo de ação e principais efeitos adversos relacionados ao seu uso, por vezes, irracional.

Considerando que os resultados positivos encontrados mostram-se relacionados a fatores como, doses elevadas ou combinações com outros fármacos, como tentativa de melhorar a eficácia ou ajustar falhas nos mecanismos de ação desses fármacos frente ao SARS-CoV-2, é essencial que estudos clínicos randomizados mais robustos sejam realizados, com número maior de participantes, abrangendo diferentes grupos da população, visando resultados mais confiáveis. Além disso, nestes estudos devem ser envolvidos grupos controle a fim de evitar viés na interpretação dos dados. Dessa maneira, após comprovação in vivo, os medicamentos somente poderão ser utilizados com segurança e sem prejuízos ao organismo humano, após comprovação de seus efeitos in vivo.

Neste contexto, o profissional farmacêutico tem um papel importante na promoção do uso racional de medicamentos na pandemia de COVID-19, orientando sobre o uso destes medicamentos citados. Destaca-se o fato de que as farmácias são, na 
maioria das vezes, a primeira porta de acesso à saúde e muitos indivíduos se dirigem a elas desprovidos de informações para comprar medicamentos que são divulgados na mídia como eficazes no tratamento da COVID-19 ou preventivos. Cabe ao farmacêutico realizar uma comunicação assertiva com o paciente e informá-lo dos riscos de utilizar medicamentos sem comprovação científica, sobretudo se o indivíduo utilizar o medicamento em altas doses, se faz uso de outros medicamentos ou se apresenta outras comorbidades.

\section{Agradecimentos}

Ao FNDE pelo apoio financeiro.

\section{Referências}

Alam, M. T., Murshed, R., Bhiuyan, E., Saber, S., Alam, R. F., \& Robin, R. C. (2020). A case series of 100 COVID-19 positive patients treated with combination of ivermectin and doxycycline. Journal of Bangladesh College of Physicians and Surgeons, 10-15.https://doi.org/10.3329/jbcps.v38i0.47512

Belayneh A. (2020). Off-Label Use of Chloroquine and Hydroxychloroquine for COVID-19 Treatment in Africa Against WHO Recommendation. Research and reports in tropical medicine, 11, 61-72. https://doi.org/10.2147/RRTM.S269936

Caly, L., Druce, J. D., Catton, M. G., Jans, D. A., \& Wagstaff, K. M. (2020). The FDA-approved drug ivermectin inhibits the replication of SARS-CoV-2 in vitro. Antiviral research, 178, 104787.https://doi.org/10.1016/j.antiviral.2020.104787

Dragojevic Simic, V., Miljkovic, M., Stamenkovic, D., Vekic, B., Ratkovic, N., Simic, R., \& Rancic, N. (2021). An overview of antiviral strategies for coronavirus 2 (SARS-CoV-2) infection with special reference to antimalarial drugs chloroquine and hydroxychloroquine. International journal of clinical practice, $75(3)$, e13825. https://doi.org/10.1111/ijcp.13825

Fróes, A.C., Pasquinelli, F., Quintela, M.M., Pimentel, A.C. \& Roman-Torres, C.V.G. (2020). The role of interleukin-1beta in the pathophysiology of periodontal disease: a literature review. Research, Society and Development, 9(7),1-14, e674974773. http://dx.doi.org/10.33448/rsd-v9i7.4773

Gautret, P., Lagier, J. C., Parola, P., Meddeb, L., Mailhe, M., Doudier, B., ... \& Raoult, D. (2020). Hydroxychloroquine and azithromycin as a treatment of COVID-19: results of an open-label non-randomized clinical trial. International journal of antimicrobial agents, 56(1), 105949. https://doi.org/10.1016/j.ijantimicag.2020.105949

González-Paz, L. A., Lossada, C. A., Moncayo, L. S., Romero, F., Vera-Villalobos, J., Pérez, A. E., \& Alvarado, Y.J. (2021). A Bioinformatics Study of Structural Perturbation of 3CL-Protease and the HR2-Domain of SARS-CoV-2 Induced by Synergistic Interaction with Ivermectins. Biointerface Research in Applied Chemistry, 11(2), 9813 - 9826. https://doi.org/10.33263/BRIAC112.98139826

He, F., Deng, Y., Li, W. (2020). Coronavirus disease 2019: What we know? Journal of Medical Virology, 92, 719-725. https://doi.org/10.1002/jmv.25766

Hussain, I., Hussain, A., Alajmi, M. F., Rehman, M. T., \& Amir, S. (2021). Impact of repurposed drugs on the symptomatic COVID-19 patients. Journal of infection and public health, 14(1), 24-38. https://doi.org/10.1016/j.jiph.2020.11.009

Kaur, K., Kaushal., S., \& Kaushal, I. (2020). Therapeutic status of hydroxychloroquine in COVID-19: A review. Journal of Anaesthesiology Clinical Pharmacology, 36, 160. https://dx.doi.org/10.4103\%2Fjoacp.JOACP_313_20

Kaur, H., Shekhar, N., Sharma, S., Sarma, P., Prakash, A. \& Medhi, B. (2021). Ivermectin as a potential drug for treatment of COVID-19: an in-sync review with clinical and computational attributes. Pharmacol Rep, 73(3),736-749.https://doi.org/10.1007/s43440-020-00195-y

Kern C., Schöning V., Chaccour C.\& Hammann F. (2021) Modeling of SARS-CoV-2 Treatment Effects for Informed Drug Repurposing. Frontiers in Pharmacology, 12.https://doi.org/10.3389/fphar.2021.625678

Klimke, A., Hefner, G., Will, B., \& Voss, U. (2020). Hydroxychloroquine as an aerosol might markedly reduce and even prevent severe clinical symptoms after SARS-CoV-2 infection. Medical hypotheses, 142, 109783. https://doi.org/10.1016/j.mehy.2020.109783

Lucchetta, R. C., \& de Carvalho Mastroianni, P. (2019). Rational use of chloroquine and hydroxychloroquine in times of COVID-19. Revista de Ciências Farmacêuticas Básica e Aplicada, 40, 1-5.

Maisonnasse, P., Guedj, J., Contreras, V., Behillil, S., Solas, C., Marlin, R., ... \& Le Grand, R. (2020). Hydroxychloroquine use against SARS-CoV-2 infection in non-human primates. Nature, 585(7826), 584-587.

Mallhi, T. H., Ahmad, A., Butt, M. H., Misbah, S., Khan, Y. H., \& Alotaibi, N. H. (2020). Chloroquine and hydroxychloroquine in COVID-19: practice implications for healthcare professionals. Journal of the College of Physicians and Surgeons--Pakistan: JCPSP, 30(10), 124-128. https://doi.org/10.29271/jcpsp.2020.10.124

Mohan, P., Sinha, S., Uppal, R. (2020). Role of ivermectin in COVID-19: Wishful thinking or scientific optimism. J Mar Med Soc, 22 (3), 27-31. https://doi.org/10.4103/jmms.jmms_146_20 
Molina, J. M., Delaugerre, C., Le Goff, J., Mela-Lima, B., Ponscarme, D., Goldwirt, L., \& de Castro, N. (2020). No evidence of rapid antiviral clearance or clinical benefit with the combination of hydroxychloroquine and azithromycin in patients with severe COVID-19 infection. Medecine et maladies infectieuses, 50(4), 384.https://doi.org/10.1016/j.medmal.2020.03.006

Momekov, G.\& Momekova, D. (2020). Ivermectin as a potential COVID-19 treatment from the pharmacokinetic point of view: antiviral levels are not likely attainable with known dosing regimens. Biotechnology \& Biotechnological Equipment, 34 (1), 469-474.https://doi.org/10.1080/13102818.2020.1775118

Nina, P. B., \& Dash, A. P. (2020). Hydroxychloroquine as prophylaxis or treatment for COVID-19: What does the evidence say?. Indian journal of public health, 64, S125-S127. https://doi.org/10.4103/ijph.IJPH_496_20

Paumgartten, F. J. R., \& Oliveira, A. C. A. X. D. (2020). Off label, compassionate and irrational use of medicines in Covid-19 pandemic, health consequences and ethical issues. Ciencia \& saude coletiva, 25, 3413-3419. https://doi.org/10.1590/1413-81232020259.16792020

Pereira B. B. (2020). Challenges and cares to promote rational use of chloroquine and hydroxychloroquine in the management of coronavirus disease 2019 (COVID-19) pandemic: a timely review. Journal of toxicology and environmental health. Part B, Critical reviews, 23(4), 177-181. https://doi.org/10.1080/10937404.2020.1752340

Rajter, J.C., Sherman, M.S., Fatteh, N., Vogel, F., Sacks, J., \& Rajter, J.J. (2020). Use of Ivermectin Is Associated With Lower Mortality in Hospitalized Patients With Coronavirus Disease 2019. Chest, 159(1), 85-92.http://dx.doi.org/10.2139/ssrn.3631261

Singh, A. \& Gupta, V. (2021). SARS-CoV-2 therapeutics: how far do we stand from a remedy? Pharmacol Rep, 73 (3), 750-768. https://doi.org/10.1007/s43440020-00204-0

Schmith, V. D., Zhou, J., \& Lohmer, L. R. (2020). The approved dose of ivermectin alone is not the ideal dose for the treatment of COVID-19. Clinical Pharmacology \& Therapeutics, 108(4), 762-765. https://doi.org/10.1002/cpt.1889

Tang, W., Cao, Z., Han, M., Wang, Z., Chen, J., \& Sun, W. (2020). Hydroxychloroquine in patients mainly with mild to moderate COVID-19: an open-label, randomized, controlled trial. medRxiv, 10.https://doi.org/10.1101/2020.04.10.20060558

Willis, V. C., Arriaga, Y., Weeraratne, D., Reyes, F., \& Jackson, G. P. (2020). A Narrative Review of Emerging Therapeutics for COVID-19. Mayo Clinic proceedings. Innovations, quality \& outcomes, 4(6), 745-758. https://doi.org/10.1016/j.mayocpiqo.2020.07.004

Zou, L., Dai, L., Zhang, X., Zhang, Z., \& Zhang, Z. (2020). Hydroxychloroquine and chloroquine: a potential and controversial treatment for COVID-19. Archives of pharmacal research, 43(8), 765-772. https://doi.org/10.1007/s12272-020-01258-7 